\section{Take rural road trips to promote science}

As the March for Science in Washington DC on 22 April gathers momentum, we argue that it should be followed by ongoing scientific outreach to rural US communities. This would encourage their participation in the broader science conversation, fostering improved relationships with, and trust in, the scientific community.

These goals cannot be achieved just through the Internet and specialist research papers. We must rid ourselves of the stereotype of the ivory tower academic. As well as touring the international conference circuit, we should take local road trips to convey the exciting insights we garner through our research. Rural communities are just as interested as those in cities in how our work could apply to them and their environment.

Some US political institutions have gained rural America's trust because they listened and responded to local needs while becoming part of the community. Scientists must do the same.

Adam Moreno NASA Ames Research Center, Moffett Field, California, USA.

Christine S. Olsen Oregon State University, Corvallis, Oregon, USA. adam.l.moreno@nasa.gov

\section{Blind spot in the March for Science}

In attempting to counteract the lies currently rebranded as 'alternative facts' and 'post-truth', the organizers of the US March for Science on 22 April reveal a blind spot for the afactual the realm of narratives, norms and values that is not directly dependent on facts. Enthusiasm for the breakthroughs enabled by the scientific method is justifiable. But we must remind ourselves that laws and theories derived from verifiable observations do not constitute all (or even most) of our knowledge.

Many politically engaged scientists cling to the notion that they carefully gather facts about all matters of life into a kind of collage of knowledge, and arrive at judgements based on dispassionate analysis. But this process inevitably entails complex subjective, and ultimately opaque, operations, such as evaluating, interpreting, decontextualizing, generalizing and networking.

Values drive electoral behaviour, and public discourse is shaped by efforts to control the narrative. It is therefore essential for the fields of enquiry that are primarily devoted to evaluating narratives and norms - the humanities - to be at the forefront of efforts to improve public discourse. The ability to interpret, articulate and shape the afactual is still of the utmost importance.

Alex Holznienkemper Baylor University, Texas, USA alex.holznienkemper@outlookcom

\section{National biosafety standards differ}

China's new maximum biosafety level-4 (BSL-4) laboratories plan to perfect containment practices by starting work with the virus responsible for Crimean-Congo haemorrhagic fever (CCHF), which requires only BSL-3 containment under Chinese regulations (Nature 542, 399-400; 2017). US researchers, however, must use a BSL-4 facility for culturing and handling this deadly pathogen. Is the United States overestimating the potential biohazard of CCHF, or is China underestimating it?

It seems that countries without endemic CCHF, such as the United States and the United Kingdom, err on the side of caution by requiring BSL-4, whereas those such as China that experience CCHF outbreaks seem more amenable to allowing less stringent containment of the virus (M. Weidmann et al. J. Gen. Virol. 97, 2799-2808; 2016). This illustrates how different conclusions of expert biological-risk assessors result in differing biosafety practices.

And in countries such as Uzbekistan, where CCHF outbreaks occur, but which have no BSL-4 or BSL-3 facilities, and which forbid the export of pathogen samples even for diagnosis, clinicians and researchers are forced to make do as best they can.

Frank Alexander Hamill MRIGlobal, Gaithersburg, USA. ahamill@mriglobal.org

\section{Make animal models more meaningful}

Non-human primates are our most intelligent animal models, but are, paradoxically, the ones most severely deprived of the environmental substrates needed for healthy brain development. For animal models to be biologically relevant, we need to remove the stress of captivity. We must identify and reproduce those aspects of their natural environments that are essential for their well-being.

Research animals need the freedom to explore, problemsolve and overcome challenges. These are not options in a mouse cage that is typically 280,000 times smaller than a mouse's natural range, or 7 million times smaller in the case of a rhesus macaque.

Laboratory caging alters nervous, endocrine and immune functionality. Psychological responses to natural fluctuations in food, shelter and predation are hijacked by uncontrolled artificial stimuli such as experimenter gender, chow phyto-oestrogen content and ultrasonic noise.

Radio telemetry now enables us to record molecular, cellular and physiological changes in roaming animal subjects. These technologies can help us to understand the ecological factors necessary for the animals welfare and for the biological development that is under study. Garet Lahvis Oregon Health \& Science University, Portland, USA. lahvisg@ohsu.edu

\section{Boost diversity in biomedical research}

What works, and why, for diversity initiatives in business and on campus? To answer this question, and to scale up programmes across a wide range of institutions, the Association of Public and Land-Grant Universities, its Coalition of Urban Serving Universities and the Association of American Medical Colleges have issued a report entitled Increasing Diversity in the Biomedical Research Workforce: Actions for Improving Evidence (see go.nature.com/2nhz7qn).

The report finds that a learning environment that has students from mixed backgrounds encourages students' exploration while reducing racial prejudice. Also, ethnically diverse authorships produce better science. As a physician and researcher, I have witnessed how inclusiveness in medical education translates into moreeffective and -comprehensive research and care.

In some fields, only $4 \%$ of postdocs are from ethnic groups that are widely underrepresented in education (see go.nature.com/2na5y5g). We need to gather more data on implicit bias and find out how best to attract and retain greater numbers of these students.

To that end, we urge more partners in government, industry, philanthropy and academia to test the available models and to research new options. University leaders can then direct resources to the best solutions.

Michael V. Drake Ohio State University, Columbus, USA. drake.379@osu.edu 